\title{
Author Correction: Environment-responsive nanophores for therapy and treatment monitoring via molecular MRI quenching
}

\author{
Charalambos Kaittanis ${ }^{1}$, Travis M. Shaffer ${ }^{1,2}$, Anuja Ogirala ${ }^{1}$, Santimukul Santra ${ }^{3}$, J. Manuel Perez ${ }^{4}$, \\ Gabriela Chiosis ${ }^{1}$, Yueming $\mathrm{Li}^{1}$, Lee Josephson ${ }^{5}$ \& Jan Grimm ${ }^{1}$
}

Correction to: Nature Communications https://doi.org/10.1038/ncomms4384, published online 04 March 2014

This Article contains an error in Fig. 6. In panel b, the left-hand image is mistakenly described as showing fluorescence before treatment, while it in fact shows the same white light image as the right-hand panel without fluorescent overlay to better visualize the tumour location. A correct version of Fig. $6 \mathrm{~b}$ is presented below as Figure 1. The error has not been corrected in the original version of the Article.

Published online: 18 April 2019

\begin{abstract}
(c) Open Access This article is licensed under a Creative Commons Attribution 4.0 International License, which permits use, sharing, adaptation, distribution and reproduction in any medium or format, as long as you give appropriate credit to the original author(s) and the source, provide a link to the Creative Commons license, and indicate if changes were made. The images or other third party material in this article are included in the article's Creative Commons license, unless indicated otherwise in a credit line to the material. If material is not included in the article's Creative Commons license and your intended use is not permitted by statutory regulation or exceeds the permitted use, you will need to obtain permission directly from the copyright holder. To view a copy of this license, visit http://creativecommons.org/licenses/by/4.0/.
\end{abstract}

(c) The Author(s) 2019

\footnotetext{
${ }^{1}$ Molecular Pharmacology and Chemistry Program, Memorial Sloan Kettering Cancer Center, 1275 York Avenue, New York, New York 10065, USA. ${ }^{2}$ Department of Chemistry, Hunter College of the City University of New York, Graduate Center, New York, New York 10065, USA. ${ }^{3}$ Department of Chemistry, Pittsburg State University, 1701 S Broadway Street, Pittsburg, Kansas 66762, USA. ${ }^{4}$ NanoScience Technology Center, University of Central Florida, 12424 Research Parkway, Suite 400, Orlando, Florida 32826, USA. ${ }^{5}$ Center for Advanced Medical Imaging Sciences, Massachusetts General Hospital, Building 149, 13th Street,

Charlestown, Massachusetts 02129, USA. Correspondence and requests for materials should be addressed to J.G. (email: grimmj@mskcc.org)
} 


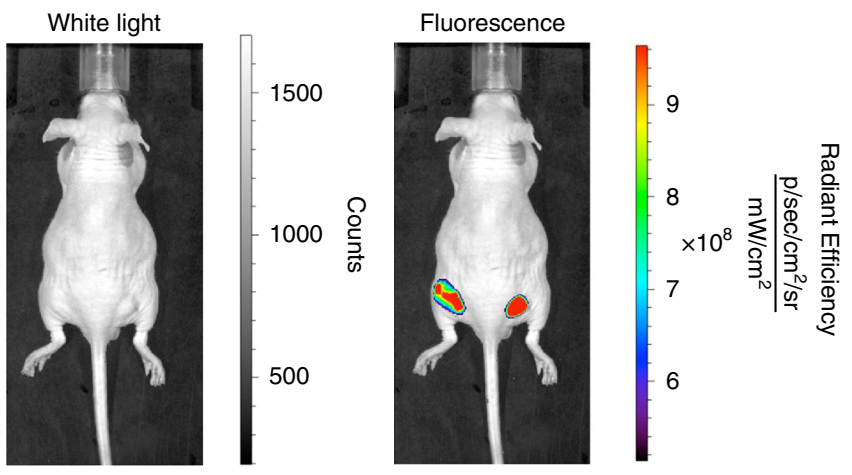

Fig. 1 